SHS Web of Conferences 7, 02007 (2014)

DOI: $10.1051 /$ shsconf / 20140702007

(C) Owned by the authors, published by EDP Sciences, 2014

\title{
Campus Road Greening Landscape Analysis and Plants Disposition Suggestions-- A case of the campus in Tsinghua University
}

Pan Jiangqiong, Sun Mengnan

Tsinghua University Repair Center Park and Forestry Department, Tsinghua University Green University Office, 100084 Beijing, China

\begin{abstract}
The paper takes the campus of Tsinghua University as a case, through the analysis on characteristics, landscape aesthetics and landscape functions of the campus road greening, proposes the suggestions of plants disposition on the aspects that the campus road greening plays the beautification function of road greening, embodies the cultural function of road greening, attaches traffic function of road greening, etc.
\end{abstract}

Keywords. campus; road; greening landscape; plant disposition

\section{Introduction}

Campus road greening landscape is the main part of campus landscape and shoulders the important function of campus traffic evacuation, at the same time, bears the functions of campus beautification and cultural education. Therefore, study on university campus road greening landscape is of great significance to improve the quality of campus road greening, create a better campus environment, so as to realize the purpose of university environmental education.

In the late $1970 \mathrm{~s}$, the urban greening entered the stage of rapid development after the approach of "jointing parts into clusters, combining dot, line and face" of urban greening is proposed. After the 1980 s, there appeared the approaches of "broad environment greening" represented by Tianjin in the north and "ecological landscaping" represented by Shanghai in the south. At the end of 1999, there's a green coverage of $591,000 \mathrm{hm} 2$ in 667 urban built-up areas in the whole country with the greening rate of $23 \%$, green coverage ratio of $27.44 \%$ and per capita public green area of $6.5 \mathrm{~m} 2$. The Planning and Design Specifications of Urban Street Greening set by related department in 1994 could be interpreted as "different urban streets and traffic, the basic traffic developed based on space" according to green street greening. It reflects the development level of productivity, people's aesthetic consciousness and all kinds of wishes. Therefore, the content of urban street greening isn't single and should be considered comprehensively. Of course, the urban street greening also exists in colleges and universities.

\section{Campus road greening characteristics analysis}

\subsection{Road greening characteristics of each function sector of university campus}

Campus greening rate of Tsinghua University reaches $43 \%$, of which about $35 \%$ of the greening area is road greening.

This is an Open Access article distributed under the terms of the Creative Commons Attribution License 4.0, which permits unrestricted use, distribution, and reproduction in any medium, provided the original work is properly cited. 
According to the use function, Tsinghua University campus can be divided into the following three main areas and traffic hubs of the surrounding areas. The characteristics of the road greening are not identical. The main road greening status is shown in Table 1 below.

Table 1. Greening status questionnaire of each area in Tsinghua University.

\begin{tabular}{ccccc}
\hline Item & Teaching area & Living area & Office area & Traffic hubs \\
\hline Plant species (No.) & 35 & 42 & 38 & 12 \\
Plant disposition mode & Inter-planting & $\begin{array}{c}\text { Linear planting, } \\
\text { isolated planting, } \\
\text { group planting }\end{array}$ & $\begin{array}{c}\text { Isolated } \\
\text { planting, } \\
\text { linear planting }\end{array}$ & $\begin{array}{c}\text { Isolated } \\
\text { planting }\end{array}$ \\
Number of plants(trees $\left./ \mathrm{m}^{2}\right)$ & 0.12 & 0.23 & 0.09 & 0.01 \\
Plant color (summer) & Green & Green, red, purple, yellow & Green, purple & Creen \\
\hline
\end{tabular}

The above table reflects the basic characteristics of the road greening of each main area in Tsinghua University. We can obtain their main greening characteristics by analysis and investigation.

(1) The green belts in the teaching area are neat and plant disposition is also neat type. However, the plant species and the colors are monotone. Tall arbors are more. The seasonal aspect change is also very monotonous.

(2) Due to the pursuit of natural and relaxed style in the living area, and the larger space range, both the plant species and the plant colors are abundant, and the plant disposition mode is also very flexible. However, the lawns with small shrubs are priority in this area. There are less tall arbors. Especially in part of the new-built dormitory areas, extremely lack of the cover of tall arbors. There are more characteristic garden ornaments in this area.

(3) The office area is similar to the teaching area.

(4) Due to the traffic situations at the traffic hubs are more complex, therefore, basically there is no landscape and greening. And the plants growth situation is also poor.

\subsection{Investigation and analysis on the characteristics of the campus main trunk road greening}

In order to further study on campus road landscape in Tsinghua, this paper has carried on thorough investigation and analysis on the present landscape situation of thirteen main trunk roads in the campus of Tsinghua. The thirteen main trunk roads are the vast majority of transportation activity places in Tsinghua, which are the main parts of the campus road landscape. The investigation contents include the parameters such as street trees, green belts and road greening coverage rate. See table 2 below.

Table 2. Greening characteristics of campus main trunk roads greening.

\begin{tabular}{ccccc}
\hline $\begin{array}{c}\text { Road number } \\
\text { and description }\end{array}$ & Street trees species & $\begin{array}{c}\text { Bilateral green } \\
\text { belts trees species }\end{array}$ & $\begin{array}{c}\text { Bilateral green } \\
\text { belts width }\end{array}$ & $\begin{array}{c}\text { Road greening } \\
\text { coverage rate }\end{array}$ \\
\hline $\begin{array}{c}\text { No.1 Road } \\
\text { East-West }\end{array}$ & $\begin{array}{c}\text { Eucommia ulmoides, ginkgo, } \\
\text { sycamore sycamore }\end{array}$ & 45 kinds & $28 \mathrm{~m}$ & $94 \%$ \\
$\begin{array}{c}\text { Trunk Road } \\
\text { No.2 Road }\end{array}$ & $\begin{array}{c}\text { Sophora japonica, populus } \\
\text { canadensis moench,eucommia } \\
\text { ulmoides, sycamore }\end{array}$ & 26 kinds & $22 \mathrm{~m}$ & $\begin{array}{c}\text { South sector } 92 \% \\
\text { North sector } 46 \%\end{array}$ \\
$\begin{array}{c}\text { Trunk Road } \\
\text { No.3 Road }\end{array}$ & Populus tomentosa, sycamore & 12 kinds & $16 \mathrm{~m}$ & \\
9003 Bldg. & Pouth Road & & &
\end{tabular}


No.4 Road

Academy of

Arts and Design

West Road

No. 5 Road

East Main Bldg.

East Road

No. 6 Road

Teaching Bldg.

East Road

No. 7 Road

Gu Yue Tang

West Road

No. 8 Road

Lotus Pond

West Road

No. 9 Road

No. 10 Dining

Hall South Road

No. 10 Road

Youth

Apartment East

Road

No. 11 Road

Zijing C Bldg.

South Road

No. 12 Road

Zijing C Bldg.

North Road

No. 13 Road

Zijing W Bldg.

South Road

$$
\text { Cedrus }
$$

18 kinds

$14 \mathrm{~m}$

$46 \%$

Populus tomentosa

64 kinds

$20 \mathrm{~m}$

$96 \%$

Populus tomentosa, sycamore, sophora japonica

18 kinds

$11 \mathrm{~m}$

21 kinds

$23 \mathrm{~m}$

$87 \%$

Weeping willow, mongolian
oak

186 kinds

$56 \mathrm{~m}$

South sector $93 \%$

North sector less than $20 \%$

Sophora japonica, populus tomentosa, Chinese juniper, sycamore

Sophora japonica

25 kinds

$16 \mathrm{~m}$

$90 \%$

Ginkgo

12 kinds

$18 \mathrm{~m}$

Less than $20 \%$

Sycamore

9 kinds

$4 \mathrm{~m}$

Less than $20 \%$

Aesculus chinensis

11 kinds

$12 \mathrm{~m}$

Less than $20 \%$

It can be seen from the above table:

(1) The greening coverage rate of Tsinghua University campus road is higher, but due to the smaller street trees, the good shade has not formed on newly built or newly reconstructed roads, such as No. $11,12,13$ roads.

(2) The green belts on both sides of the campus roads in Tsinghua University is wider and the green area is larger. However, the green belts of newly built student apartment area is narrower and the green area is smaller. For example, the green belts of No. 12 Road (Zijing C Bldg. North Road) is only 4 m wide.

(3) The green plants species on bilateral green belts of the roads in the campus of Tsinghua University is abundant. The number of the green plants species on bilateral green belts of No. 8 Road (Lotus Pond West Road) is close to two hundred, however, the number of the green plant species on road green belts is relatively fewer in the newly built student apartment area.

(4) The street trees on bilateral green belts of the campus roads in Tsinghua University are nonuniform. Some road has three or four kinds of street trees, for example, No. 9 Road (No. 10 Dining Hall South Road) has four kinds of street trees. This is not conducive to build high quality characteristic landscape.

(5) Populus tomentosa, sophora japonica are the main street trees. Although the two street trees are the common street trees species in Beijing. However, the characteristics of the catkins and serious 
Huai petrel's pests, populus tomentosa and sophora japonica are not suitable for the greening of the campus roads with big pedestrians, non-motor vehicle traffic flow. ${ }^{[1]}$

\section{Aesthetic analysis on campus main trunk road greening landscape}

To further evaluate the campus road landscape, this paper based on the aesthetic characteristics of road greening-beautiful degree, posture, color, seasonal aspect, designed the questionnaire and carried on evaluation on the landscape of the campus main trunk roads in Tsinghua University. The obtained data are statistically analyzed in accordance with the "arithmetic average method" and the evaluation values are obtained. Based on a 10-point scale, 10, 7, 5 are assigned respectively for investigation and statistics. The specific results are in the following table:

Table 3. Investigation results of campus main trunk roads greening landscape.

\begin{tabular}{ccccccc}
\hline Road number and description & $\begin{array}{c}\text { Beautiful } \\
\text { degree }\end{array}$ & Posture & Color & $\begin{array}{c}\text { Seasonal } \\
\text { aspect }\end{array}$ & Gradation & Total score \\
\hline $\begin{array}{c}\text { No.1 Road } \\
\text { East-West Trunk Road }\end{array}$ & 8.96 & 8.42 & 7.52 & 7.45 & 7.56 & $\mathbf{3 9 . 9 1}$ \\
$\quad$ No.2 Road & 7.47 & 8.56 & 6.54 & 6.46 & 7.12 & 36.15 \\
$\begin{array}{c}\text { South-North Trunk Road } \\
\text { No.3 Road }\end{array}$ & 6.37 & 6.78 & 5.98 & 6.21 & 6.67 & $\mathbf{3 2 . 0 1}$ \\
$\begin{array}{c}\text { 9003 Bldg. South Road } \\
\text { No.4 Road }\end{array}$ & & & & & & 34.1 \\
Academy of Arts and Design & 6.57 & 7.12 & 6.51 & 6.76 & 7.14 & 38.33 \\
$\begin{array}{c}\text { West Road } \\
\text { No. 5 Road }\end{array}$ & 7.46 & 8.13 & 6.86 & 7.96 & 7.92 & 36.62 \\
East Main Bldg. East Road \\
$\begin{array}{c}\text { No. 6 Road } \\
\text { Teaching Bldg. East Road }\end{array}$
\end{tabular}

It can be seen that the highest scores are Lotus Pond West Road and East-West Main Trunk Road. Both have the characteristics of high greening rate and abundant plant species, etc. And the lowest scores are 9003 Bldg. South Road and Zijing C Bldg. North Road. I 
The beautiful degree of campus plant landscape is related to the posture of the plants, the color transformation of the plants, the seasonal aspect transformation of the plants, the collocation of plants gradation, as well as the use of the space. Any of these aspects usually do not fully determine the beautiful degree of the plant landscape. ${ }^{[2]}$

\section{Analysis on campus main trunk road greening landscape function}

As the main trunk roads of the campus, the greening function mainly reflects in the following respects.

\subsection{Transportation function}

Road greening is one of the important factors influencing the traffic safety. Good road greening can not only improve the ecological environment and have the beautification effect, can also relieve drivers' nervous mood, improve road safety from the subjective. ${ }^{[3]}$ At the same time, a reasonable plant disposition can also effectively coordinate people stream and traffic flow distribution, ensure unimpeded traffic, and reduce the accident loss, protect the safety of people's lives. Fig.1 is the road greening of the south sector of the South-North Main Trunk Road in the Tsinghua campus. It can be seen that the settings of the green belts divides the motor vehicle lanes and non-motor vehicle lanes, which guarantees the traffic of this main trunk road with big traffic flow.

\subsection{Beautification function}

Road greening landscape can break the depressing feeling of the rigid pavement, form a clear green landscape interface, increase the environmental colour, and foil the campus environment. For example, the green belts in front of the Main Building break the traditional form of central avenue. The form of the combination of the green landscape with the bilateral roads forms Tsinghua characteristic landscape.

\subsection{Division}

The connection, partition, enclosure functions of the green plants together with the roads form separation of the function areas. As shown in the figure, the trees wall on the south side of the Gym make the Gym South Road and Gym Front Plaza form a uniform encirclement region, which is not only beneficial to the traffic but also can form a square.

\subsection{Shadowing decoration}

Road greening landscape can cover a decoration on the inelegant road landscape, which reaches the effect of beautifying the environment. At the same time, greening also can also design into all sorts of design to beautify the roads and exaggerate the atmosphere, and different plants can produce different landscape effects, such as arbors can divide space, shrubs can make the space produce privacy, liana plants can beautify and greening corridor metope, and ground plants can cover to produce flat aesthetic impression. ${ }^{[4]}$

\subsection{Cultural metaphor}

Road greening in the campus has a strong function of the cultural metaphor, especially in Tsinghua University. Plants for road greening may display a certain regional culture characteristics. The anthropomorphic plants, plant landscape, and the combination of plants can form the landscape characteristics with a certain cultural connotation. 


\section{Conclusion and discussion}

\subsection{Campus road greening plant disposition should play the beautification function of the road greening}

Beautiful degree of plant landscape and posture of plants directly affect the beautification function of roads. When campus road greening, we should choose growing strong plants with beautiful posture and good shape, especially on the choice of street trees, we should pay more attention to the plants that have uniform tree canopy and shape, the same size of tree diameter and breast height and heighly uniform branch points; at the same time, we also should pay attention to select drought resistance, cold resistance tree species that have good resistance to diseases and pests and so on, such as ginkgo, liriodendron, sycamore, linden, aesculus chinensis and other good street trees.

Tree colour and seasonal aspect are the important influence factors in the campus road landscape. We should reasonablly use, collocate color, plant some species with obvious colour and seasonal change, such as acer truncatum, ginkgo, metasequoia, smoke tree, red maple, cornus alba and other colored tree species. With the change of seasons, the street trees also will have corresponding changes, and form the characteristic landscape to create a colorful campus road landscape, improve the campus environmental atmosphere, and also can effectively prevent and reduce traffic accidents. ${ }^{[5]}$

\subsection{Campus road greening plant disposition should reflect the cultural function of the road greening}

In addition to the beautification function, university campus greening also bears the cultural and educational function.

At the same time, many plants themselves also contain profound plant culture and have good educational function. The educational function of plant culture lies in that people can enjoy all sorts of modelling of ornamental plants and appreciate all kinds of beauty of plants, such as, their upright and outspoken beauty, noble and pure beauty, elegant and ease beauty, natural and unrestrained beauty, etc. Then, people can be edified and infected by the true, the good and the beauty. The emotions, the "life attitudes" and the values change subtly and profoundly. ${ }^{[6]}$ The plants emotionally satisfy the aesthetic needs and people obtain spiritual enjoyment and aesthetic pleasure; the plants have important roles in excavating the potential of the human brain, enlightening inspiration thinking, and training creative talents.

\subsection{Plant disposition of the campus road greening should pay attention to the traffic function of the road greening}

The tree shape (tree height and crown) of the road greening plants should be controlled and be kept consistent in a long time. They should have the following engineering properties: dense and elastic branches without a large number of clipping; long service life, fewer pests, stronger resistance to smoke and wind damage; beautiful tree shape full of seasonal aspect changes; straight arbor tree trunk, neat branches, big thick shadow, high branch points (3.5m or above generally required), and keep the permeability and do not impede the safety of vehicle driving, and the fruit trees do not harm to pedestrians. The trees with catkins, poison seta, odor and polluted seeds or fruits should not be chosen.

\section{References}

1. Zhong Hanmou. Do a Good Job in Landscaping, Create a Garden City [J]. Guangdong Garden, 1995(02).

2. Li Fushuang, Wei Hongjie. Native Tree Species in the Discussion of Application in Garden Greening [J]. Shelter Forest Science and Technology, 2006(05). 
3. Wu Yinghua, Zhu Lin, Liu Meijuan. Introduction to Suqian City Landscaping Problems and Countermeasures [J]. Jiangsu Forestry Science and Technology, 2004(02).

4. $\mathrm{Li}$ Weidan. Introduction to Forestry Industrialization Development and Construction of Ecological Culture [J]. Science and Technology to become Rich the Wizard, 2011(27).

5. Yao Lianghong. Implementing Ways and Measures for the Sustainable Development of Forestry [J]. Green Technology, 2011(08).

6. Huang Jianmin. Shallow Theory of Modern Forestry Development and Ecological Civilization Construction [J]. Green Technology, 2010(10). 